\title{
SISTEM PREDIKSI PENJUALAN GAMIS TOKO QITAZ MENGGUNAKAN METODE SINGLE EXPONENTIAL SMOOTHING
}

Oleh:

\author{
Salman Alfarisi \\ Program Studi Teknik Informatika \\ Fakultas Teknik, Matematika dan Ilmu Pengetahuan Alam \\ Universitas Indraprasta PGRI \\ Email : \\ salman.hotaru@gmail.com
}

\begin{abstract}
ABSTRAK
Untuk mendapatkan laba yang besar pada suatu perusahaan adalah dengan menentukan prediksi penjualan pada bulan berikutnya. Prediksi merupakan salah satu kunci dari keberhasilan penjualan karena dengan nilai prediksi penjualan yang bisa dijadikan panduan sebagai acuan untuk menentukan suatu penjualan produk. Metode Single Exponential Smoothing digunakan untuk menentukan prediksi penjualan pada periode berikutnya. Metode exponential smoothing merupakan metode peramalan yang cukup baik untuk peramalan jangka panjang, jangka menengah maupun jangka pendek, terutama pada tingkat operasional suatu perusahaan, dalam perkembangan dasar matematis dari metode exponential smoothing. Data yang akan diolah adalah data pada Toko Qitaz, pada tahun 2016 dan disajikan pada data perbulan. Hasil yang didapatkan dari penelitian ini adalah hasil analisa dari metode eksponensialtunggal untuk memperoleh informasi prediksi penjualan dan tingkat keakuratannya dengandata MAD, MSE, MAPEuntuk mencari error terkecil. Pada tahap berikutnya dibangun sebuah sistem prediksi penentuan permintaan konsumen dengan menggunakan metode pengembangan sistem waterfall dan pembuatan software yang dirancang menggunakan bahasa pemrograman Java dengan editor NetBeans dan database MySQL. Dari hasil pengujian terhadap sistem yang telah dibuat, system dapat meramalkan data penjualan gamis pada toko Qitaz sehingga sistem dapat membantu toko Qitaz dalam mengambil keputusan pada perkiraan stok produk dengan tepat.
\end{abstract}

Kata Kunci : Prediksi, Penjualan, Single Exponential Smoothing, Sistem

\section{A. PENDAHULUAN}

Perkembangan dunia computer dan internet saat ini telah tumbuh dengan sangat pesat, seiring dengan kebutuhan manusia yang semakin banyak dan semakin kompleks.Komputer kini telah digunakan secara luas di berbagai bidang, contoh: bisnis, kesehatan, pendidikan, psikologi, permainan dan lain sebagainya. Halini mendorong para ahli danpengembang untuk semakin mengembangkan 
komputer agar dapat membantu kerja manusia atau bahkan lebih dari itu. Berkembangnya teknologi mulai dari hardware sampai kebutuhan softwarenya pun meningkat. Banyak perusahaan, home industry dan toko sekalipun sekarang mereka banyak yang menggunakan komputer yang dilengkapi system informasi yang bertujuan untuk melakukan proses penyimpanan data, perkiraan penjualan di periode berikutnya, dan sebagainya. Oleh karena itu Toko Qitaz yang saat ini masih melakukan pengaturan bisnisnya secara manual memiliki beberapa kendala. Salah satu kendalanya adalah banyaknya barang yang bisa menjadi kendala dalam melakukan proses bisnisnya dan berakibat pada kesalahan memperkirakan penjualan barang untuk pengiriman selanjutnya.

Dari masalah di atas muncul pemikiran untuk membuat sebuah sistem yang dapat membantu dalam melakukan proses mengelola barang dan peramalan penjualan barang untuk periode berikutnya. Diharapkan dengan adanya sistem informasi ini, akan membuat data- data barang terkomputerisasi dengan baik antara database, user interface, dan user itu sendiri. Sistem informasi yang dilengkapi dengan adanya system peramalan penjualan barang diharapkan dapat menambah kinerja dan pelayanan terhadap para pelanggan dalam hal penyuplaian barang agar tidak kehabisan stok barang. Berdasarkan alasan di atas,akhirnya peneliti ingin membuat suatu sistem prediksi penjualan gamis dengan metode single exponential smoothing dengan tujuan untuk memprediksi penjualan pada 1 periode (per bulan).

\section{B. KAJIAN PUSTAKA}

\section{Peramalan}

Dalam melakukan analisa ekonomi atau analisa kegiatan usaha/bisnis perusahaan, haruslah diperkirakan apa yang terjadi, baik dalam bidang ekonomi atau dalam dunia usaha/bisnis pada masa yang akan datang. Usaha untuk melihat situasi dan kondisi pada masa yang akan datang merupakan usaha untuk memperkirakan pengaruh situasi dan kondisi yang berlaku terhadap perkembangan di masa yang akan datang. Kegiatan untuk memperkirakan apa yang akan terjadi pada masa yang datang, disebut peramalan (forecasting).

Heizer \& Render menyatakan bahwa peramalan adalah suatu seni dan ilmu pengetahuan dalam memprediksi peristiwa-peristiwa pada masa mendatang (Heizer \& Render, 2015). Peramalan akan melibatkan mengambil data historis (seperti penjualan tahun lalu ) dan memproyeksikan mereka ke masa yang akan datang dengan model matematika.

Stevenson \& Shoung menyatakan bahwa peramalan (forecast) adalah pernyataan mengenai nilai yang akan datang dari variable seperti permintaan (Stevenson \& Shoung, 2013). Artinya ramalan adalah prediksi mengenai masa depan. Sedangkan Syofian menyatakan bahwa prakiraan ramalan adalah kegiatan memprediksi nilai masa depan, dengan dasar pengetahuan atau nilai masa lalu yang dipersiapkan. Prakiraan ramalan mencakup penggunaan data historis, dengan memproyeksikannya untuk masa depan yang menggunakan jenis model matematis (Syofian, 2013). 
Berdasarkan beberapa definisi diatas, pada hakikatnya peramalan merupakan suatu keputusan tentang kemungkinan masa yang akan datang yang didasarkan fakta-fakta ekonomi sekarang dan sejarah masa lalu. Sebelum melakukan peramalan harus diketahui lebih dulu persoalan dalam pengambilan keputusan. Dengan adanya peramalan manajemen dapat segera menyiapkan langkah paling baik dalam mengatasi permasalahan dan dapat bersiap-siap memanfaatkan situasi jika terjadi perkembangan yang lebih baik dalam peramalan. Peramalan yang menjadi titik tolak bagi tindakan perusahaan adalah ramalan penjualan. Pengertian ramalan penjualan adalah proyeksi teknis permintaan konsumen yang potensial pada masa yang akan datang dengan menggunakan berbagai pendekatan. Hal ini sangat berhubungan dengan kegiatan produksi. Dalam proses produksi kegiatan yang dilaksanakan dalam peramalan adalah untuk menentukan jumlah permintaan konsumen terhadap suatu produk yang dilakukan pada awal proses perencanaan dan untuk kepentingan proses pengendalian produksi. Oleh sebab itu perangkat lunak sangat dibutuhkan, untuk mendukung peramalan permintaan konsumen untuk mempercepat, mempermudah dan menghindari hitungan dengan tangan yang kemungkinan terjadi kesalahan.

\section{Tipe Peramalan}

Organisasi menggunakan 3 tipe peramalan utama dalam merencanakan operasional untuk masa mendatang (Heizer \& Render, 2015) :

1. Peramalan Ekonomi (Economic Forecast)

Menangani siklus bisnis dengan memprediksikan tingkat inflasi, uang yang beredar, mulai pembangunan perumahan, dan indikator perencanaan lainnya.

2. Peramalan Teknologi (Technological Forecast)

Berkaitan dengan tingkat perkembangan teknologi, dimana dapat menghasilkan terciptanya produk baru yang lebih menarik, yang diperlukan pabrik dan perlengkapan yang baru.

3. Peramalan Permintaan (Demand Forecast)

Adalah proyeksi atas permintaan produk atau jasa dari perusahaan. Peramalan mendorong keputusan sehingga para manajer memerlukan informasi dengan segera dan akurat mengenai permintaan yang sesungguhnya.

\section{Pendekatan Peramalan}

Menurut (Heizer \& Render, 2015), terdapat dua pendekatan umum untuk peramalan, hanya terdapat dua cara untuk mengatasi seluruh permodelan keputusan.Salah satu adalah analisis kuantitatif ,yang satunya lagi adalah pendekatan kualitatif. Didalam metode peramalan kualitatif tidak digunakan perhitungan-perhitungan dengan rumus dan metode yang pasti melainkan melalui pendapat dari berbagai pihak. Metode peramalan kualitatif antara lain didasarkan pada penilaian dan opini (Opini dewan Eksekutif, Opini bagian Penjualan ), Survei Pasar, Metode Delphi. Sedangkan Metode peramalan kuantitatif adalah metode peramalan yang sangat mengandalkan pola data historis yang dimiliki. Pada metode kuantitatif menggunakan metode yang berhubungan dengan ilmu statistik dan matematika, sehingga dapat dipertanggungjawabkan secara ilmiah. 
Metode kuantitatif dikelompokan menjadi dua jenis yaitu : analisis sebab-akibat (Causal Methods ) yang didasarkan atas pengguna analisa pola hubungan antara variabel yang akan diperkirakan dengan variabel lain yang mempengaruhinya dan analisa deret berkala ( Time Series ) yang pada umumnya selalu berdasarkan atas penggunaan analisa pola hubungan antara variabel yang akan diperkirakan dengan variabel waktu. Metode ini merupakan metode peramalan yang memperkirakan permintaan konsumen/penjualan periode yang akan datang dengan menggunakan data historis.

Ada 3 (tiga) teknik untuk menghitung deret berkala terdiri dari : metode rata-rata bergerak (Moving Average), rata-rata bergerak tertimbang (weight average) dan penghalusan eksponensial (Exponential Smoothing). Penjelasan dari ketiga teknik menghitung rata-rata pada metode analisa deret berkala (Time Series) adalah sebagai berikut :

1. Metode Rata-Rata Bergerak (Moving Average)

Rata-rata bergerak (Moving Average) mengembangkan suatu model berdasarkan hasil perhitungan rata-rata dari sebagian besar penelitian dengan menggunakan persamaan :

$$
\mathrm{F}_{1}=1\left(\mathrm{~A}_{\mathrm{t}-1}+\mathrm{A}_{\mathrm{t}-2}+\ldots \ldots \ldots+\mathrm{A}_{\mathrm{z}}\right) / \mathrm{N}
$$

Penjelasan :

$$
\begin{array}{ll}
\mathrm{F} 1 & =\text { Hasil peramalan untuk periode } \mathrm{t} \\
\mathrm{N} & =\text { jumlah data penelitian } \\
\mathrm{A} \mathrm{t} & =\text { data historis penjualan/permintaan konsumen. }
\end{array}
$$

A $\mathrm{t}-2 \ldots \mathrm{Az}=$ data historis penjualan/permintaan konsumen periode 2 hingga $t-n$

2. Metode Rata-rata Bergerak Tertimbang (Weighted Moving Average).

Metode ini sama dengan rata-rata bergerak, tetapi nilai terbaru dalam deret berkala diberikan beban lebih besar untuk menghitung peramalan.Secara matematis , rata-rata bergerak tertimbang ditunjukan sebagai berikut :

Rata-rata bergerak tertimbang $=\mathrm{w}_{\mathrm{n}} \mathrm{A}_{\mathrm{t}-\mathrm{n}}+\mathrm{w}_{\mathrm{n}-1} \mathrm{~A}_{\mathrm{t}-(\mathrm{n}-1)}+\ldots \mathrm{w}_{1} \mathrm{~A}_{\mathrm{t}-1}$

Dimana :

$$
\begin{array}{ll}
\mathrm{Wn} & =\text { bobot yang diberikan pada nilai terbaru } \\
\text { A t }-1 & =\text { nilai aktual pada periode } \mathrm{t}-1
\end{array}
$$

3. Metode Penghalusan Eksponensial (Exponential Smoothing)

Peramalan Penghalusan Eksponensial (Exponential Smoothing) merupakan salah satu kategori metode time series yang menggunakan pembobotan data masa lalu untuk melakukan peramalan. Besarnya bobot berubah menurun secara eksponensial bergantung pada data histori.Berdasarkan bobot yang digunakan ,metode Exsponental terbagi menjadi tiga jenis yaitu : 
a. MetodeSingle Exponential Smoothing

Bentuk matematis dari metode Single Exponential Smoothing ditunjukan sebagai berikut:

$$
F_{t}=\alpha A_{t-1}+(1-\alpha) F_{t-1}
$$

Dimana :

$$
\begin{array}{ll}
F_{t} & =\text { Ramalan Baru } \\
F_{t-1} & =\text { Ramalan Sebelumnya } \\
\alpha & =\text { Konstanta Penghalusan } \\
A_{t-1} & =\text { Permintaan aktual periode Sebelumnya }
\end{array}
$$

b. Metode Double Exponential Smoothing (Metode Holt)

Metode ini merupakan pengembangan dari Single Exponential dimana menambahkan unsur trend pada bobot perhitungan ,sehingga pada Double Exponential Smoothing (Metode Holt) kita memberikan dua jenis bobot pada perhitungan yaitu level $(\alpha)$ dan trend $(\beta)$.

Bentuk matematis dari Double Exponential Smoothing ditunjukan sebagai berikut :

$$
\begin{aligned}
& A_{t}=\alpha Y_{t}+(1-\alpha)\left(A_{t-1}+T_{t-1}\right) \\
& T_{t}=\beta\left(A_{t}-A_{t-1}\right)+(1-\beta) T_{t-1} \\
& F_{t+m}=A_{t}+T_{t} m
\end{aligned}
$$

At $=$ nilai pemulusan eksponensial

$\alpha=$ konstanta pemulusan untuk data $(0<\alpha<1)$

$\beta=$ konstanta pemulusan untuk estimasi trend $(0<\beta<1)$

$\mathrm{Yt}=$ nilai aktual pada periode $\mathrm{t}$

$\mathrm{Tt}=$ estimasi trend

$\mathrm{F}(\mathrm{t}+\mathrm{m})=$ Nilai ramalan

c. Metode Triple Exponential Smoothing

Metode Triple Exponential Smoothing atau dapat dikenal dengan nama "Winter's Method", merupakan pengembangan dari Double Exponential dimana melakukan peramalan dengan tiga parameter dengan bobot yang berbeda yaitu level ( $\alpha$ ), trend $(\beta)$ dan seasonal ( $\gamma$ ). Berdasarkan tipe musiman ( Triple Exponential Smoothing ) dibagi menjadi dua yaitu: Multiplicative Seasonal Model dan Additive Seasonal Model. Perbedaan antara Multiplication Seasonal Model dengan Additive Seasonal adalah sebagai berikut :

Pada Multiplicative Seasonal Model yaitu mengalikan hasil perhitungan level dan trend dengan perhitungan Seasonal. Sedangkan 
Additive Seasonal Model yaitu menambahkan hasil perhitungan level dan trend dengan perhitungan Seasonal.

$$
\begin{aligned}
& A_{t}=\alpha \frac{Y_{t}}{S_{t-L}}+(1-\alpha)\left(A_{t-1}+T_{t-1}\right) \\
& T_{t}=\beta\left(A_{t}-A_{t-1}\right)+(1-\beta) T_{t-1} \\
& S_{t}=\mu \frac{Y_{t}}{A_{t}}+(1-\mu) S_{t-L} \\
& \hat{Y}_{t+p}=\left(A_{t}+T_{t} p\right) S_{t-L+p}
\end{aligned}
$$

At $=$ nilai pemulusan eksponensial

$\alpha=$ konstanta pemulusan untuk data $(0<\alpha<1)$

$\beta=$ konstanta pemulusan untuk estimasi trend $(0<\beta<1)$

$\mu=$ konstanta pemulusan untuk estimasi musiman $(0<\mu<1)$

$\mathrm{Yt}=$ nilai aktual pada periode $\mathrm{t}$

$\mathrm{Tt}=$ estimasi trend

$\mathrm{St}=$ estimasi musiman

$\mathrm{L}=$ panjangnya musim

$\mathrm{p}=$ jumlah periode ke depan yang akan diramalkan

\section{Mengukur Kesalahan Peramalan}

Beberapa ukuran yang digunakan dalam praktiknya untuk menghitung keseluruhan dalam kesalahan peramalan. Ukuran-ukuran ini dapat digunakan untuk membandingkan model peramalan yang berbeda, sejalan dengan untuk memonitor peramalan untuk memastikan bahwa mereka berfungsi dengan baik. Tiga ukuran yang paling terkenal adalah deviasi rata-rata yang absolut (mean absolute deviation--MAD), kesalahan rata-rata-rata yang dikuadratkan (mean squared error-MSE), dan kesalahan persentase rata-rata yang absolut (mean absolute percent error--MAPE). Tetapi disini akan ditambahkan kesalahan ratarata (mean error--ME) sebagai acuan pertama mencari nilai error

1. ME (Mean Error) atau Nilai Rata-Rata Kesalahan

$$
\mathrm{ME}=\frac{\sum \text { Aktual }- \text { Peramalan }}{\mathrm{n}}
$$

2. MAD (Mean Absolute Deviation) atau Nilai Deviasi Rata-Rata Kesalahan Absolut

$$
\mathrm{MAD}=\frac{\Sigma \mid \text { Aktual }- \text { Peramalan } \mid}{\mathrm{n}}
$$


3. MAPE (Mean Absolute Percent Error) atau Nilai Rata-Rata Kesalahan Persentase Absolut

$$
\text { MAPE }=\frac{\sum_{i-1}^{n} 100 \mid \text { Aktual }_{i}-\text { Aktual }_{i} \mid / \text { Aktual }_{i}}{n}
$$

\section{METODE PENELITIAN}

\section{Jenis Penelitian}

Jenis penelitian yang dilakukan adalah penelitian deskriptif kuantitatif. Menurut pendapat (Yusuf, 2014) pengertian deskriptif kuantitatif adalah merupakan usaha sadar dan sistematis untuk memberikan jawaban terhadap suatu masalah dan/atau mendapatkan informasi lebih mendalam dan luas terhadap suatu fenomena dengan menggunakan tahap-tahap penelitian dengan pendekatan kuantitatif Sedangkan menurut pendapat (Syofian, 2013) Penelitian deskriptif kuantitatif adalah dengan cara menggambarkan obyek penelitian pada saat sekarang berdasarkan fakta-fakta sebagaimana adanya, kemudian dianalisis dan diinterpretasikan,bentuknya berupa survei dan studi perkembangan. Sebagai kesimpulan dari pendapat diatas maka yang dimaksud dengan penelitian deskriptif kuantitatif adalah mendeskripsikan mengenai situasi-situasi atau kejadiankejadian berdasarkan fakta, dimulai dari menguraikan kriteria, kemudian sub kriteria sebagai bahan analisa dan interpretasi untuk mendukung pembuatan peramalan. serta alternatif pemilihan perangkat lunak untuk mendukung peramalan. Penelitian ini melibatkan data, perhitungan dan penarikan kesimpulan. Data tersebut diambil dari data historis dan kuesioner. Sedangkan penghitungan teknik peramalan dengan Single Exponential Smoothing Model menggunakan teknik statistika. Dari hasil penghitungan dan pembahasan tersebut diambil kesimpulan.

Selanjutnya akan didesain prototipe perangkat lunak yang mendukungnya. Metode yang digunakan untuk pengembangan sistem adalah metode waterfall sedangkan pembuatan perangkat lunak tersebut menggunakan bahasa pemrograman Java dengan database menggunakan MySQL.

\section{Metode Pengumpulan Data}

Metode pengumpulan data yang digunakan dalam penelitian ini adalah sebagaiberikut :

1. Riset kepustakaan ( Library Research)

Penelitian kepustakaan dilakukan untuk mendapatkan data sekunder maupun teori-teori yang berhubungan dengan penelitian. Hal tersebut dilaksanakan dengan cara membaca dan mempelajari buku-buku yang tersedia di perpustakaan.

2. Riset Lapangan (Field research)

Penelitian lapangan adalah suatu usaha untuk mendapatkan data - data primer dan informasi sebenarnya dengan cara turun langsung ke lapangan. Peneliti mengadakan peninjauan langsung ke lokasi responden ditempat 
produksi maupun di tempat berjualannya, sehingga diperoleh gambaran tentang masalah yang menjadi objek penelitian. Cara yang digunakan peneliti adalah dengan menggunakan kuesioner atau angket, yaitu dengan menyebarkan angket kepada responden, dimana responden diminta untuk mengisi angket yang telah disediakan oleh peneliti. Responden dalam penelitian ini adalah pemilik toko Qitaz.

\section{Teknik Pengolahan dan Analisa Data}

Pada penelitian ini menggunakan pendekatan kuantitatif deskriptif melalui analisis statistik yaitu metode Single Exponential Smoothing. Setelah itu akan dilakukan melalui tingkat pengujian kesalahan (error) yaitu ME (Mean Error), MAD (Mean Absolute Deviation), MAPE (Mean Absolute Percentage Error), MSE (Mean Square Error) .Kegiatan analisis datanya meliputi pengolahan data dan penyajian data, melakukan perhitungan untuk mendeskripsikan data dengan menggunakan uji statistik. Dalam penelitian ini terdapat dua jenis untuk pengolahan dan analisa data yaitu : data historis dan data kuesioner sebagai pendukung serta data perangkat lunak.

Penjelasan pengolahan dan analisa data sebagai berikut :

1. Pengolahan dan Analisa Data Historis menggunakan teknik : Single Exponential Smoothing Model, seperti yang sudah dijelaskan dalam Tinjauan Pustaka.

2. Pengolahan dan Analisa Perangkat Lunak menggunakan bagan alir data berbentuk Flowchart, untuk pengembangan perangkat lunak menggunakan metode waterfall, pengkodean menggunakan bahasa pemrograman Java serta untuk database menggunakan MySQL.

\section{HASIL DAN PEMBAHASAN}

\section{Deskripsi Data}

Data yang diperlukan dalam penelitian ini diperoleh melalui instrument kuesioner yang berisi data historis penjualan perbulan selama 1 tahun ( tahun 2016) dari responden dan data dari hasil wawancara kepada pemilik toko Qitaz, dimana datanya adalah sebagai berikut : 
Tabel 1.

Data Penjualan Gamis Toko Qitaz Januari s/d Desember 2016

\begin{tabular}{cc}
\hline BULAN & AKTUAL \\
\hline Januari & 105 \\
Februari & 115 \\
Maret & 130 \\
April & 130 \\
Mei & 120 \\
Juni & 130 \\
Juli & 140 \\
Agustus & 115 \\
September & 125 \\
Oktober & 120 \\
November & 130 \\
Desember & 140 \\
\hline Sumber: Diolah Peneliti
\end{tabular}

Dari data diatas akan dijadikan bentuk grafik untuk dapat di analisis berdasarkan data periodik.

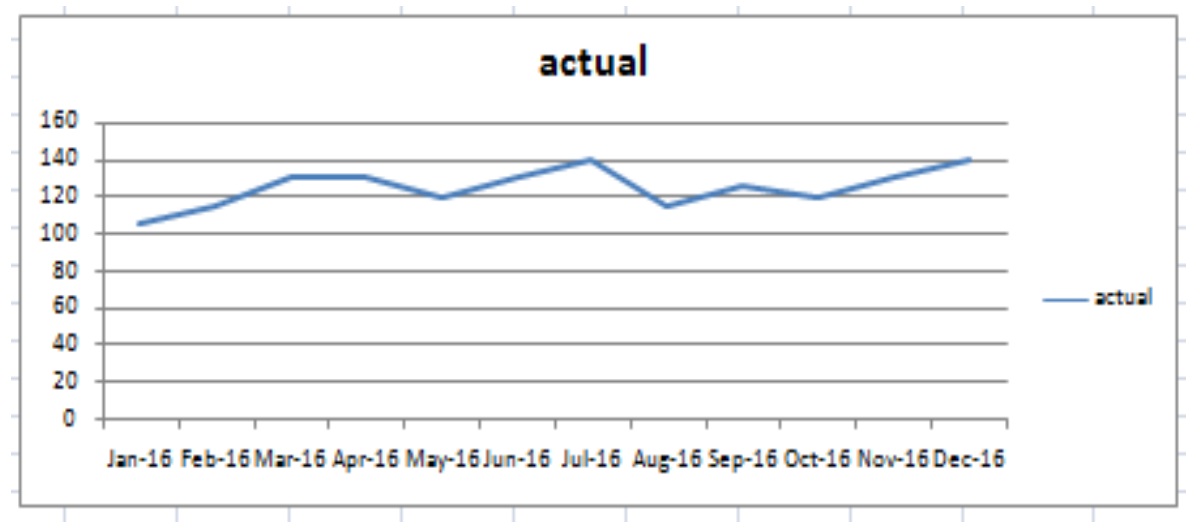

Sumber: Diolah Peneliti

Gambar 1

Grafik Penjualan Gamis Toko Qitaz Januari-Desember 2016

\section{Analisis Data dan Pembahasan}

Dari data yang tersedia, maka selanjutnya diolah dengan single exponential smoothing. 
Pada pengolahan data menggunakan single exponential smoothing dilakukan peramalan dengan satu kali penghalusan saja, dengan menggunakan rumus:

$$
F_{t}=\alpha A_{t-1}+(1-\alpha) F_{t-1}
$$

Dimana, $F_{t}=$ Ramalan Baru, $F_{t-\mathbf{1}}=$ Ramalan Sebelumnya, $\alpha=$ Konstanta Penghalusan dan $A_{t-\mathbf{1}}=$ Permintaan aktual periode sebelumnya.Peramalan dilakukan juga dengan cara meminimalkan selisih (error) terhadap data diatas. Minimalisasi dilakukan dengan metode manual dengan cara memasukkan nilai $\alpha$ $=0.1$ sampai 0.9. Dengan meminimkan error, akan didapat hasil peramalan yang paling optimum. Nilai error yang dimaksud adalah nilai perhitungan ME (Mean Error), MAD (Mean Absolute Deviation), MAPE (Mean Absolute Percentage Error), MSE (Mean Square Error)

Hasil analisis peramalan yang paling optimum dengan error yang paling minimum didapatkan dengan memasukkan nilai $\alpha=0.6$ dan $\alpha=0.7$. Berikut adalah hasil perhitungan dengan memasukkan nilai $\alpha=0.6$ :

Tabel 2.

Data Peramalan Toko Qitaz Januari s/d Desember 2016 metode Single Exponential Smoothing dengan $\alpha=0.6$

\begin{tabular}{|c|c|c|c|c|c|c|c|c|}
\hline \multirow{2}{*}{$\begin{array}{l}\text { month } \\
\text { Jan-16 }\end{array}$} & \multirow{2}{*}{$\begin{array}{r}\text { actual } \\
105\end{array}$} & \multirow{2}{*}{$\begin{array}{r}\text { forecast } \\
105\end{array}$} & \multirow{2}{*}{$\begin{array}{l}\text { error } \\
0\end{array}$} & \multicolumn{2}{|c|}{ abserror \% error } & \multirow{2}{*}{$\begin{array}{l}\text { sq. error } \\
0\end{array}$} & \multirow{2}{*}{ alpha } & \\
\hline & & & & 0 & $0 \%$ & & & \\
\hline Feb-16 & 115 & 105 & 10 & 10 & $9 \%$ & 100 & 0.6 & \\
\hline Mar-16 & 130 & 111 & 19 & 19 & $15 \%$ & 361 & & \\
\hline $\mathrm{Apr}_{\mathrm{pr}}-16$ & 130 & 122 & 8 & 8 & $6 \%$ & 58 & ME: & 4 \\
\hline May-16 & 120 & 127 & -7 & 7 & $6 \%$ & 48 & MAD: & 9 \\
\hline Juก-16 & 130 & 123 & 7 & 7 & $6 \%$ & 52 & MAPE : & $7 \%$ \\
\hline Jul-16 & 140 & 127 & 13 & 13 & $9 \%$ & 166 & MSE: & 121 \\
\hline Aug-16 & 115 & 135 & -20 & 20 & $17 \%$ & 394 & & \\
\hline Sep-16 & 125 & 123 & 2 & 2 & $2 \%$ & 4 & & \\
\hline Det-16 & 120 & 124 & -4 & 4 & $3 \%$ & 17 & & \\
\hline Nov-16 & 130 & 122 & 8 & 8 & $6 \%$ & 69 & & \\
\hline Dec- -16 & 140 & 127 & 13 & 13 & $10 \%$ & 178 & & \\
\hline
\end{tabular}

Dari data diatas dapat dijelaskan beberapa hal yaitu, month adalah bulan terjadinya penjualan. actualadalah data penjualan perbulan. forecast adalah peramalan untuk bulan berikutnya. error adalah selisih dari data actual dan forecast. abs error adalah nilai absolut error. \% error adalah persentase untuk tiap error dan sq.error adalah nilai kuadrat dari error.

ME merupakan rata-rata error yang didapatkan dari penjumlahan masingmasing nilai error, lalu dibagi dengan jumlah bulan. MAD adalah nilai rata-rata dari absolut error yang didapat dari penjumlahan masing-masing nilai abs error, lalu dibagi dengan jumlah bulan. MAPE adalah rata-rata persentase nilai error yang didapat dari penjumlahan masing-masing nilai \% error, lalu dibagi dengan 
jumlah bulan. MSE adalah nilai rata-rata kuadrat error yang didapat dari hasil penjumlahan nilai sq.error, lalu dibagi dengan jumlah bulan.

Sedangkan grafik penghalusannya adalah sebagai berikut :

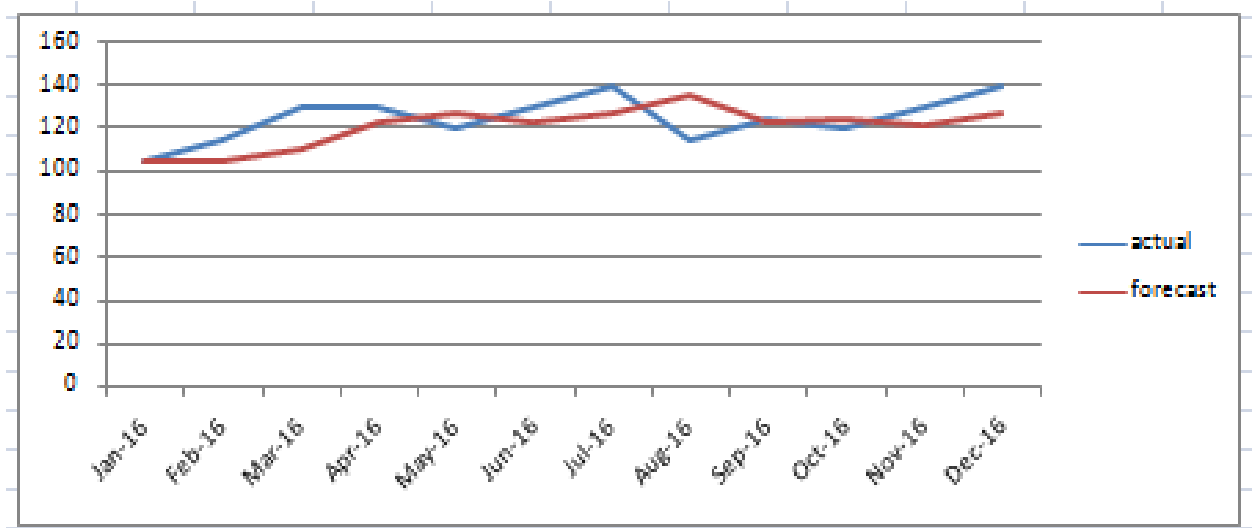

Sumber: Diolah Peneliti

Gambar 2.

Grafik penjualan Toko Qitaz Januari s/d Desember 2016 metode Single Exponential Smoothing dengan $\alpha=0.6$

Garis biru merupakan grafik dari data actual atau data penjualan tiap bulan, sedangkan garis merah adalah grafik nilai peramalan yang sudah dihaluskan.

Berikut adalah hasil perhitungan dengan memasukkan nilai $\alpha=0.7$ :

Tabel 3.

Data Peramalan Toko Qitaz Januari s/d Desember 2016 metode Single Exponential Smoothing dengan $\alpha=0.7$

\begin{tabular}{|c|c|c|c|c|c|c|c|c|}
\hline month & actual & forecast & error & abs error: & error & sq. error & & \\
\hline Jan-16 & 105 & 105 & 0 & 0 & $0 \%$ & 0 & alpha & \\
\hline Feb-16 & 115 & 105 & 10 & 10 & $9 \%$ & 100 & 0.7 & \\
\hline Mar-16 & 130 & 112 & 18 & 18 & $14 \%$ & 324 & & \\
\hline $\mathrm{Apr}-16$ & 130 & 125 & 5 & 5 & $4 \%$ & 29 & ME: & 4 \\
\hline May-16 & 120 & 128 & -8 & 8 & $7 \%$ & 70 & MAD: & 9 \\
\hline Jun-16 & 130 & 123 & 7 & 7 & $6 \%$ & 56 & MAPE : & $7 \%$ \\
\hline Jul-16 & 140 & 128 & 12 & 12 & $9 \%$ & 150 & MSE: & 121 \\
\hline Aug-16 & 115 & 136 & -21 & 21 & $19 \%$ & 455 & & \\
\hline Sep-16 & 125 & 121 & 4 & 4 & $3 \%$ & 13 & & \\
\hline Det-16 & 120 & 124 & -4 & 4 & $3 \%$ & 15 & & \\
\hline Nou-16 & 130 & 121 & 9 & 9 & $7 \%$ & 78 & & \\
\hline Dec-16 & 140 & 127 & 13 & 13 & $9 \%$ & 160 & & \\
\hline
\end{tabular}


Sedangkan tampilan grafiknya adalah sebagai berikut :

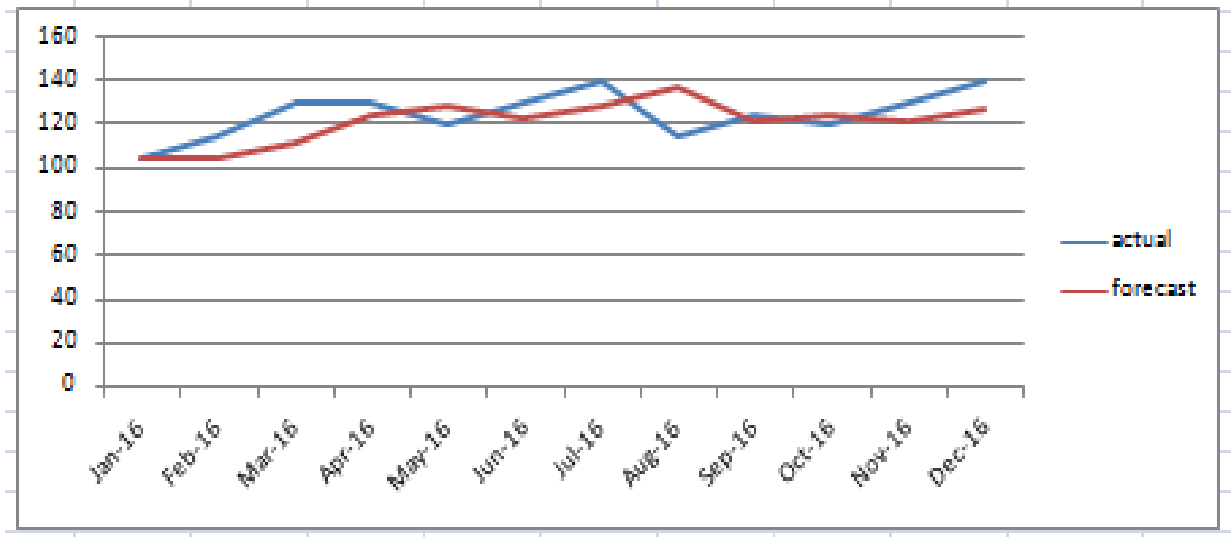

Sumber: Diolah Peneliti

Gambar 3.

\section{Grafik penjualan Toko Qitaz Januari s/d Desember 2016 metode Single} Exponential Smoothing dengan $\alpha=0.7$

Berdasarkan hasil perhitungan dari Single Exponential Smoothing Model dengan menggunakan nilai $\alpha=0.1$ sampai 0.9 ,maka didapat nilai error terkecil dengan menggunakan 4(empat) metode yang memperoleh hasil $\mathrm{ME}=4, \mathrm{MAD}=$ 9, MAPE $=7 \%$ dan MSE $=121$,yaitu dari nilai $\alpha=0.6$ dan $\alpha=0.7$. Nilai $\alpha$ inilah yang akan digunakan untuk menghitung nilai peramalan pada periode berikutnya. Single Exponential Smoothing Model digunakan pada peramalan jangka pendek, biasanya satu bulan kedepan. Model ini mengasumsikan bahwa data berfluktuasi disekitar nilai mean yang tetap ,tanpa trend atau pola pertumbuhan. Hal ini sesuai pendapat yang diungkapkan oleh William J Stevenson dan Sum Chee Chuong (2014) yang menyebutkan bahwa kecepatan penyesuaian ramalan terhadap kesalahan ditentukan dengan konstanta pemulusan $\alpha$. Semakin dekat nilai $\alpha$ dengan nol, semakin lambat ramalan akan menyesuaikan diri dengan kesalahan ramalan. Sebaliknya semakin dekat nilai $\alpha$ dengan 1,00 semakin besar kemampuan untuk merespon dan pemulusan lebih kecil.

Berikut nilai perhitungan ME (Mean Error), MAD (Mean Absolute Deviation), MAPE (Mean Absolute Percentage Error), MSE (Mean Square Error) dengan nilai $\alpha=0.1$ sampai 0.9 . 
Tabel 4.

Nilai Perhitungan ME, MAD, MAPE, MSE metode Single Exponential Smoothing

\begin{tabular}{|c|c|c|c|c|}
\hline Nilai Kesalahan & ME & MAD & MAPE & MSE \\
\hline $\boldsymbol{\alpha}=\mathbf{0 . 1}$ & 13 & 13 & $10 \%$ & 251 \\
\hline $\boldsymbol{\alpha}=\mathbf{0 . 2}$ & 9 & 11 & $8 \%$ & 171 \\
\hline $\boldsymbol{\alpha}=\mathbf{0 . 3}$ & 7 & 10 & $8 \%$ & 141 \\
\hline $\boldsymbol{\alpha}=\mathbf{0 . 4}$ & 6 & 9 & $7 \%$ & 128 \\
\hline $\boldsymbol{\alpha}=\mathbf{0 . 5}$ & 5 & 9 & $7 \%$ & 123 \\
\hline $\boldsymbol{\alpha}=\mathbf{0 . 6}$ & 4 & 9 & $7 \%$ & 121 \\
\hline $\boldsymbol{\alpha}=\mathbf{0 . 7}$ & 4 & 9 & $7 \%$ & 121 \\
\hline $\boldsymbol{\alpha}=\mathbf{0 . 8}$ & 3 & 9 & $7 \%$ & 123 \\
\hline $\boldsymbol{\alpha}=\mathbf{0 . 9}$ & 3 & 9 & $8 \%$ & 126 \\
\hline
\end{tabular}

Dari hasil pengolahan ketiga model tersebut proses selanjutnya akan dibuat rancangan konsep perangkat lunak menggunakan flowchart sebagai bagan alir program yang menggambarkan alur data atau alur pemrograman dari aplikasi yang akan dirancang untuk kebutuhan peramalan kebutuhan konsumen yang akan datang dengan alur sebagai berikut :

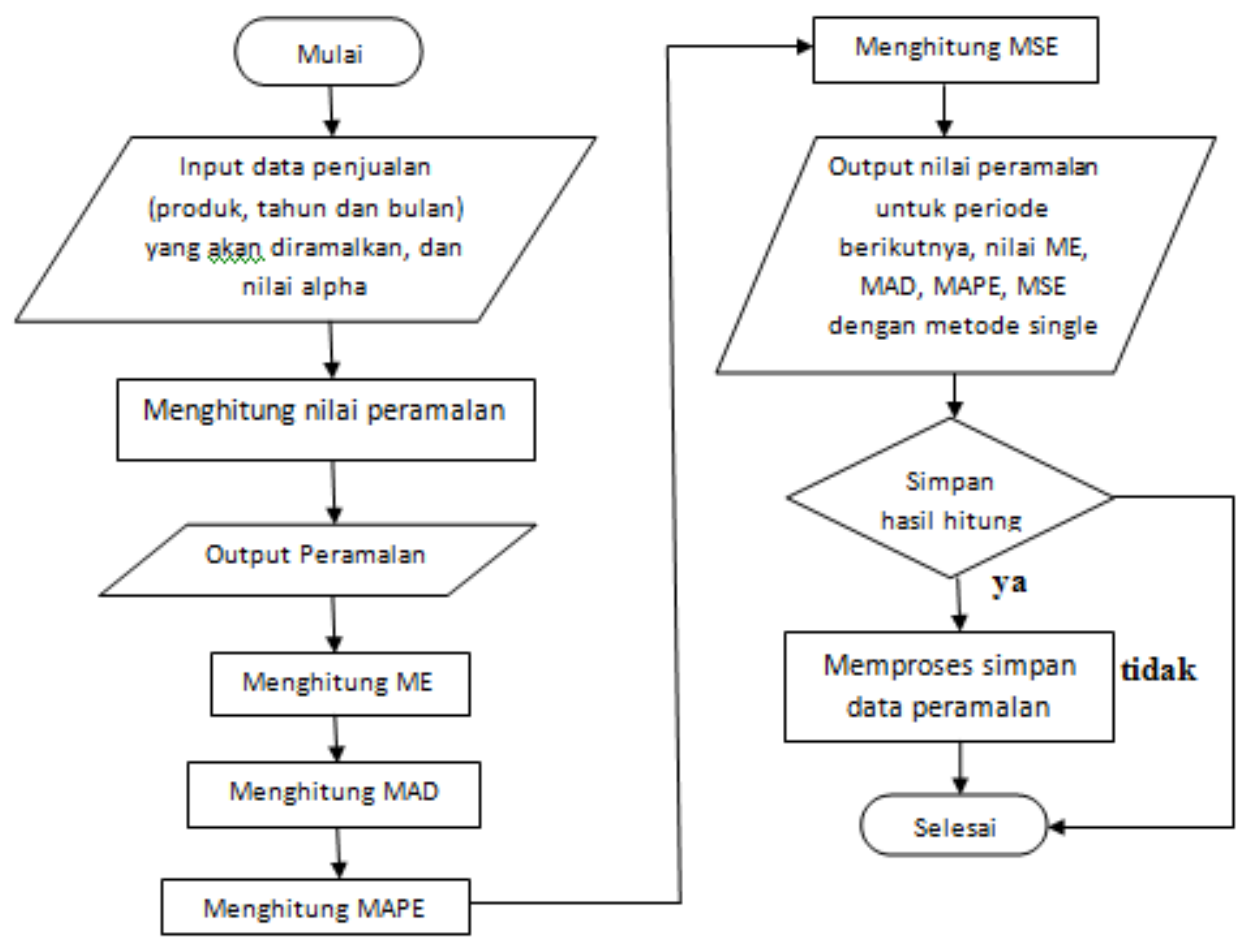

Sumber: Diolah Peneliti

Gambar 4.

Flowchart untuk metode Single Exponential Smoothing 
Bagan alir program perhitungan di atas dapat dijelaskan sebagai berikut :

1. Memasukkan data penjualan yang akan diramalkan dan nilai alpha

2. Menghitung nilai peramalan

3. Keluaran untuk proses perhitungan peramalan

4. Menghitung nilai Mean Error (ME)

5. Menghitung nilai Mean Absolute Deviation (MAD)

6. Menghitung nilai Mean Percentage Error(MAPE)

7. Menghitung nilai Mean Square Error (MSE)

8. Keluaran untuk ramalan periode berikutnya serta nilai ME, MAD, MAPE, MSE dengan metode single exponential smoothing.

Jika ingin menyimpan hasil peramalan maka komputer akan memproses penyimpanan data kemudian selesai. Jika tidak maka selesai.

\section{Sistem Peramalan}

Sistem peramalan memiliki kemampuan untuk menyimpan data penjualan dan peramalan, menghitung peramalan dengan metode single exponential smoothing serta membuat laporan hasil peramalan kepada pemilik toko Qitaz dengan mudah dan akurat sesuai dengan kebutuhan dari toko Qitaz.

Secara umum sistem ini terbagi dalam beberapa menu yaitu :

1. Halaman Login, digunakan sebagai menu awal ketika user ingin masuk kedalam sistem. Hal ini untuk menjaga agar sistem ini hanya bisa diakses oleh orang-orang yang berhak saja, yaitu user.

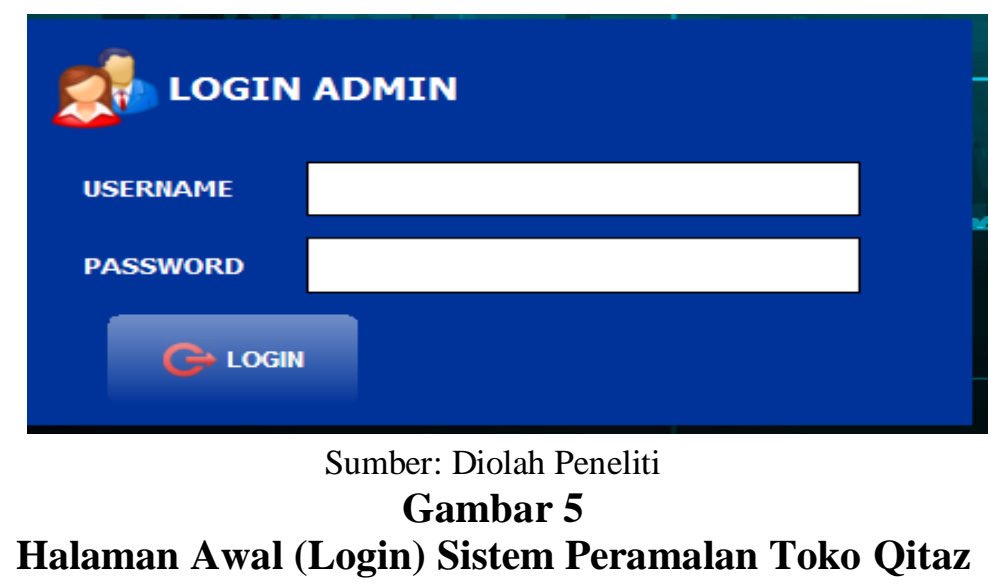

2. Penginputan data aktual, digunakan untuk memasukkan data barang berdasarkan kode barang, nama barang, bulan dan jumlah penjualan barang (nilai aktual) penjualan gamis toko Qitaz. Dalam menu tersebut ada tombol pilihan yaitu tambah ( digunakan untuk memasukkan data), edit ( untuk mengubah data jika ada kesalahan ), hapus ( untuk menghapus data jika datanya salah ), dan exit (untuk keluar dari halaman input data aktual). 


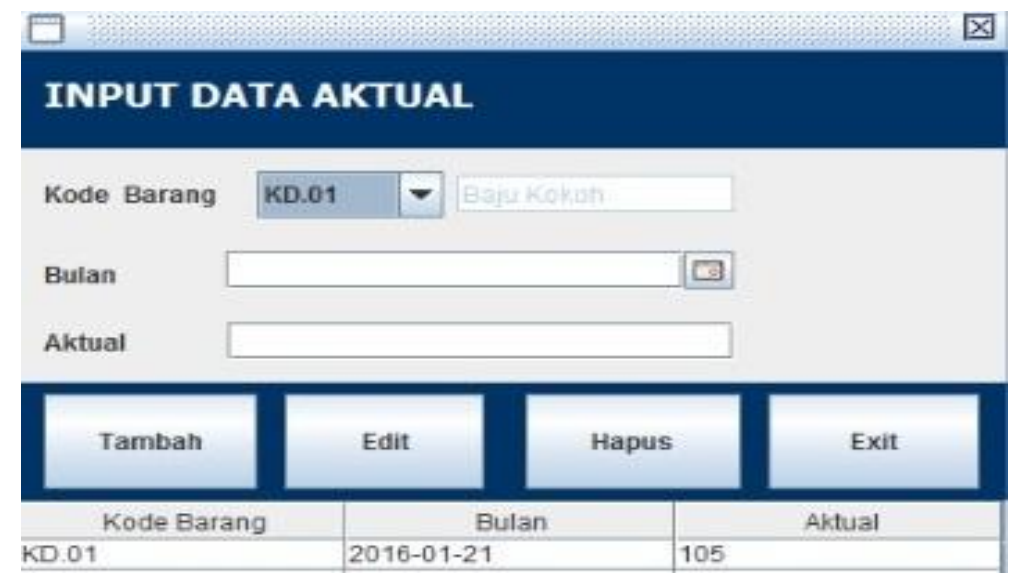

\section{Sumber: Diolah Peneliti \\ Gambar 6. \\ Form Input Sistem Peramalan Toko Qitaz}

3. Perhitungan peramalan, digunakan untuk menghitung peramalan peramalan single exponential smoothing. Untuk menghitung peramalan, terlebih dahulu user memasukkan nilai alpha, setelah itu tekan tombol hitung, lalu sistem akan menghitung dan menampilkan nilai peramalan beserta empat nilai error ( ME, MAD, MAPE,dan MSE) dilayar menu.

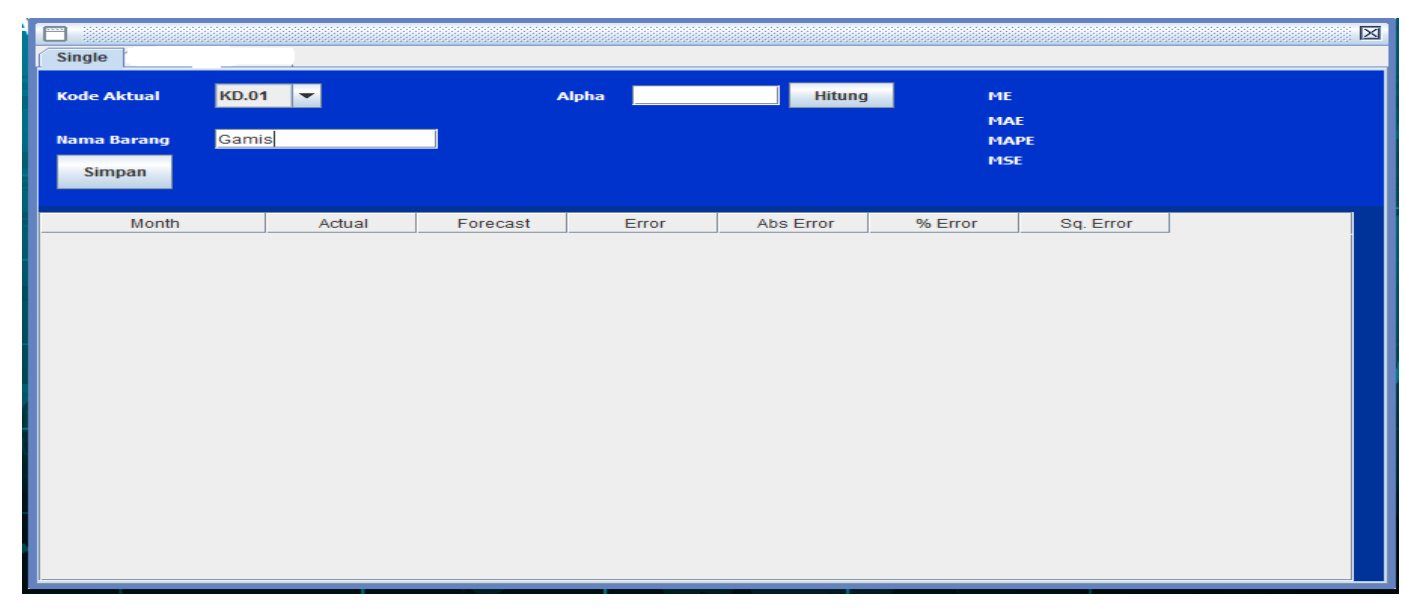

\section{Sumber: Diolah Peneliti \\ Gambar 6 \\ Form Output Sistem Peramalan Toko Qitaz}

\section{E. SIMPULAN}

Berdasarkan hasil penelitian dan uraian tersebut diatas maka.peneliti membuat kesimpulan yakni hasil perhitungan dengan metode Single Exponential 
Smoothing digunakan untuk peramalan dalam jangka pendek biasanya satu bulan kedepan. Data dari hasil perhitungannya berfluktuasi disekitar nilai mean ( ratarata ) yang tetap tanpa trend dan pertumbuhan.Dengan dibuatnya sistem aplikasi dari Single Exponential Smoothing, diharapkan pemilik toko Qitaz akan lebih mudah untuk menyimpan data penjualan gamisnya, menghitung nilai peramalan untuk periode berikutnya dan membuat laporan hasil perhitungan peramalan secara cepat dan akurat. Sehingga tujuan dan manfaat dari penelitian ini yaitu pendapatan optimal dan efisiensi biaya dapat tercapai.

\section{DAFTAR PUSTAKA}

Assauri, S. (2016). Manajemen Operasi Produksi Edisi 3. Jakarta: PT Raja Grafindo Persada.

Heizer, J., \& Render, B. (2015). Manajemen Operasi Edisi 11. Jakarta: Salemba Empat.

Stevenson, W. J., \& Shoung, S. C. (2013). Operations Management: an Asian Perspective. Jakarta: Salemba Empat.

Syofian, S. (2013). Metode Penelitian Kuantitatif dilengkapi Perbandingan Perhitungan Manual \& SPSS. Jakarta: Kencana Prenadamedia Group.

Yusuf, A. M. (2014). Metode Penelitian Kuantitatif, Kualitatif, dan Penelitian Gabungan. Jakarta: Kencana Prenadamedia Group. 